https://helda.helsinki.fi

\title{
Animacy effects on differential Goal marking
}

\section{Kittilä, Seppo Tapio}

2008-08-01

Kittilä , S T 2008 , ' Animacy effects on differential Goal marking ', Linguistic Typology , vol. 12 , no. 2 , pp. $245-268$. https://doi.org/10.1515/LITY.2008.038

http://hdl.handle.net/10138/250872

https://doi.org/10.1515/LITY.2008.038

unspecified

publishedVersion

Downloaded from Helda, University of Helsinki institutional repository.

This is an electronic reprint of the original article.

This reprint may differ from the original in pagination and typographic detail.

Please cite the original version. 


\title{
Animacy effects on differential Goal marking
}

\author{
SEPPO KITTILÄ
}

Abstract

This paper examines Differential R Marking (DRM) - i.e., the effects of animacy on the encoding of goals $(R)$, as in 'a linguist sent a book to the phonetician/to the town' - from a crosslinguistic perspective. The phenomenon comprises three types, which are distinguished based on whether $R$ can be marked in the same way as the transitive Patient or not (animate Rs usually allow this, while inanimate Rs usually surface as obliques). Even though DRM shares common features with Differential Object Marking (DOM), the two phenomena cannot be explained by the same functions. The findings of this article support the view that differences in object coding (comprising both DRM and DOM) are best explained by affectedness rather than ambiguity avoidance.

Keywords: animacy, Differential Object Marking, goal, indirect object, markedness, object, recipient

\section{Introduction}

It is received wisdom that animate or highly individuated (direct) objects receive a more elaborate linguistic coding than inanimate objects (see, among many others, Bossong 1985, Comrie 1989: 128, Foley 1999: 119, Aissen 2003, and Naess 2004). The phenomenon in question is known as "Differential Object Marking" (DOM). Two examples are given in (1) and (2):

(1) Camling (Tibeto-Burman)

a. khu-wa lungto-wa pucho(*-lai) set-yu he-ERG stone-INSTR snake(*-DAT) kill-3 'He killed a snake with a stone.'

b. khana khut(-lai) ta-set-yu you he(-DAT) 2-kill-3 'You killed him.' (Ebert 1997: 46) 


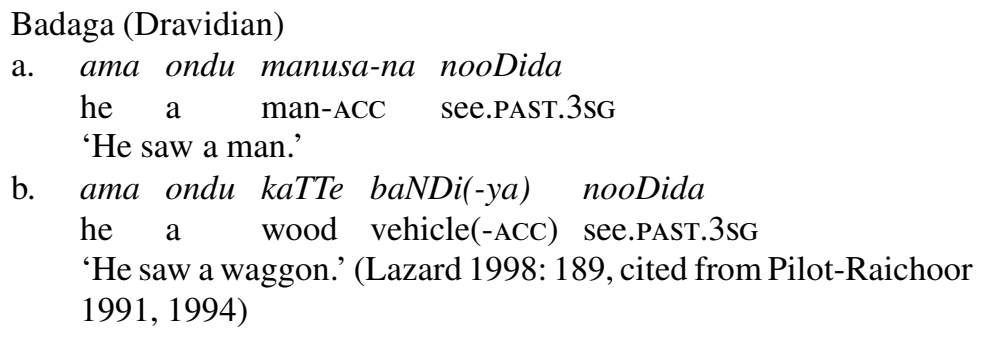

Camling and Badaga represent two slightly different manifestations of DOM. The leading principle is the same for both languages, namely more elaborate marking of animate and/or highly individuated (definite) inanimate objects in comparison with (indefinite) inanimate objects. In Camling, inanimate (nonhuman) objects cannot take the dative affix -lai, while animate (human) objects take the affix optionally. In Badaga, the accusative marker - $n a$ obligatorily attaches to animate objects, while the suffix is optional with inanimate objects.

Not only has DOM been formally described in a number of structurally different languages, a number of explanations have been advanced for it (again, see references like those above). The following functions are usually associated with DOM:

(i) Direct objects tend to be indefinite and inanimate, while subjects are usually definite and animate. The function of DOM is thus to mark subjectlike, highly prominent objects.

(ii) Animacy and definiteness are marked properties for objects. DOM thus highlights the marked nature of animate/definite direct objects.

(iii) Because animate/definite direct objects resemble subjects in light of their inherent properties, it is necessary to mark one of the arguments of basic transitive clauses overtly for its role for disambiguation. The function of DOM in nominative-accusative languages is thus to disambiguate clauses with two potential agents.

It is, for example, relatively easy to associate DOM with disambiguation, because, word order clues aside, overt coding is the only way of resolving ambiguity in clauses denoting events involving two potential agents. In a number of languages, overt case marking of arguments is dropped if their semantic roles are recoverable from context (see, e.g., Kittilä 2005 for more detailed discussion). Moreover, disambiguation follows from the subject-like properties of objects, which renders explanations like Comrie's and Aissen's plausible for DOM.

The functions of DOM that are usually recognized have recently been challenged by Naess (2004). The explanation Naess proposes instead is based on the notion of affectedness. The quote below summarizes her most important points (Naess 2004: 1203, emphasis in the original): 
On this basis we may re-cast the DOM phenomena as follows: The tendency to case-mark objects that are high in definiteness and animacy is in fact a relation of the accusative case as marking objects which are construed as being HIGHLY AFFECTED. But affectedness is as it were operationalised in terms of definiteness and animacy; when a language has to decide which kinds of objects are AFFECTED ENOUGH to receive case-marking, it may make this categorisation on the basis of more easily measurable properties on which affectedness depends. It is a simple matter to decide whether an object is definite (and so more affected than an indefinite object) or animate (and so more affected than an inanimate object), and so definiteness and animacy provide the yard-sticks by means of which affectedness may be measured. In this way we can capture the correlation between definiteness/animacy and affectedness which was discussed above, and also explain the tendency for accusative case to appear on definite/animate objects.

Even though Naess' explanation is primarily based on affectedness, she does not abandon animacy/definiteness altogether as a determining factor of DOM. Moreover, she is also well aware of the problems of defining affectedness (see also Naess 2004: 1202). As a result, Naess bases her explanation primarily on the intimate relation obtaining between animacy (humanness) and affectedness. Effects of events on human entities are perceived as more dramatic, more significant, than effects on inanimates. In many languages this distinction has been grammaticalized, which produces DOM.

This present article is also concerned with animacy effects on objects. However, in contrast to previous studies of DOM phenomena, we are dealing with the consequences of animacy for the marking of R/goals. Using R as an abbreviation for goals, both animate (including recipient and prototypical indirect objects) and inanimate, the phenomenon investigated will be labelled "Differential R Marking" (DRM). This article shows that animacy affects the marking of objects (comprising P, T, and R, see below) in a more thorough fashion than may be assumed on the basis of DOM alone. This will be achieved by examining the effects of animacy on the encoding of goals in such cases as 'a linguist sent a book to the teacher' vs. 'a linguist sent a book to Helsinki', i.e., by examining cases in which Rs differ in animacy. The article also discusses the rationale behind DRM in light of the explanations proposed for DOM. It will be shown that the explanation proposed by Naess better captures the nature of DRM. The focus of the examination lies on the motivation of DRM, but the results are applicable to object marking in more general terms. This also means that the widely accepted discriminatory view of argument marking - the idea stems from Comrie (1978: 379) and Dixon (1979: 69), the label "discriminatory" is first used by Mallinson \& Blake (1981: 91-96), as far as I know - is not applicable to explaining the marking of objects as a whole, but the indexing view seems to explain object marking in general. In other words, the function of DRM is not to distinguish between arguments (the primary function of ar- 
gument marking according to the discriminatory view), but rather to highlight certain features, such as affectedness, associated with Goals (the primary function of argument marking according to the indexing view).

Before proceeding it is essential to define the label goal/R. First, it is relevant to note that the differences between the semantic roles of recipient and goal have been neutralized in the formal discussion of DRM (Section 2). I am aware of the semantic differences between these roles, but our main focus here lies on animacy effects, and other differences are in the background in Section 2. These differences merit a study of their own, and this lies outside the scope of this article. Moreover, both recipient and goal can be seen as endpoints of transfer, which makes it possible to lump these roles together. There are also languages which accord $\mathrm{R}$ a uniform marking regardless of animacy, which also justifies seeing these as different manifestations of a single semantic role. Moreover, other factors, such as aspect and affectedness, which also contribute to the coding of R (see Kittilä 2007), are irrelevant to the examination below. The focus is on animacy alone. The roles relevant to the discussion in this article are exemplified in (3). ${ }^{1}$
a. The teacher
transferred
the book $\mathrm{T} \quad \mathrm{R}$ (animate)
to the student
A
b. The teacher transferred the book A $\mathrm{T}$ to the school
c. The teacher broke the vase A $P$

The definitions assumed here are semantic-functional in nature. This means that any way of coding the roles is relevant to the investigation below, no matter whether the roles surface as obliques or as core arguments. The term object is also occasionally used in cases where the distinction between $\mathrm{P}$ and $\mathrm{R}$ or $\mathrm{T}$ and $\mathrm{R}$ is not relevant. If it is necessary to refer to the underlying semantic roles explicitly, the labels agent (A), theme (T), goal (R), and patient $(\mathrm{P})$ will be used.

\section{The phenomenon}

\subsection{Preliminaries}

This section discusses DRM formally from a crosslinguistic perspective and proposes a formal typology. The examination is purely descriptive, i.e., it only illustrates what kinds of formal consequences animacy has for Rs. Languages

1. There are also A-R clauses, such as I went to him, but these are not relevant here. 
in which animacy does not affect the form of $\mathrm{R}$ are not discussed in this section. Three different types are distinguished according to how the differences between animate and inanimate Rs are formally manifested, labelled as (i) the core vs. oblique type, (ii) Extended Differential Object Marking, and (iii) the oblique type. Although the following examination is based on the formal differences between animate and inanimate Rs, the coding of $\mathrm{P}$ is also considered for determining whether Rs receive the same marking as transitive Ps or whether they are marked differently. This is directly related to the core vs. oblique marking of Rs: agents and constituents that receive the same coding as $\mathrm{P}$ are core arguments, while other constituents are viewed as obliques. ${ }^{2}$ The typology below is based on case marking (including also case-like particles and apdositions). In many of the cases examined there are also changes in constituent order, which also underlines the differences in status between animate and inanimate Rs (animate Rs usually occupy the slot of the P, while inanimate Rs are removed from P slot). Subtypes based on word order differences will, however, not be distinguished.

The typology below has certain similarities with (but also clear differences from) Dryer's (1986) and Haspelmath's (2005 and 2007) typologies of ditransitive constructions. First, the typology proposed below is not a typical alignment-typology, but it focuses on the animacy effects on one argument, namely $\mathrm{R}$, only. In some cases, changes in the animacy of $\mathrm{R}$ are related to changes in alignment type (in the spirit of Haspelmath 2005), but this is secondary to the discussion below. Haspelmath 2007 has more similarities with the present article, because it also discusses changes in the $\mathrm{R}$ coding (Differential Recipient Marking). However, Haspelmath's article investigates whether there is a special marking for $\mathrm{R}$ (marking different from that of $\mathrm{T}$ ) and how this interacts with animacy hierarchies. Haspelmath does not discuss the types of differential marking, but he is interested in cut-off points in animacy hierarchies (for example, whether there is a special marking for 3rd person pronouns and inanimate entities, etc.). The present article, on the other hand, is interested only in the differences between animate and inanimate Rs, while animacy hierarchies as such are not relevant. In sum, Haspelmath is interested only in whether there are differences in the coding of $\mathrm{R}$ determined by animacy, while the present article is interested in the nature of the attested differences. Animacy is also relevant to Dryer's typology, but only because recipients are typically humans, and as such they are coded as (animate) Ps in many languages. Dryer does not discuss animacy effects on Rs. All of his examples (except one) are ditransi-

2. In this article, the label oblique is defined in purely morphological terms. This means clausal constituents whose morphological marking is different from subjects and direct objects are labelled as obliques. Syntactic features of obliques and arguments (such as relativization and passivization) are not relevant here. This is in line, for example, with Blake 1994: 203-204. 
tive constructions with animate Rs. Dryer's typology is not directly relevant to the typology proposed here, even though many of the languages discussed display variation between primary/secondary object-type and the direct/indirect object-type depending on the animacy of R. This is, however, irrelevant in the present context.

\section{The core vs. oblique type}

The first type of DRM is represented by languages in which animate Rs are formally treated as Ps, while inanimate Rs are obliques. Animate Rs are thus core arguments, while inanimate Rs are seen as obliques. Three subtypes are distinguished depending on the nature of the effects animacy has on Ps and how this is manifested on Rs. This subdivision is largely based on whether a given language exhibits DOM or not.

2.1.1. The animacy-based subtype. The first subtype of the core vs. oblique type is represented by languages in which animate Rs are marked in the same way as animate Ps, while inanimate Rs are marked differently, and also differently from inanimate Ps. The type can be schematically presented as in Figure 1 .

As shown in Figure 1, animate objects receive a uniform formal treatment in the animacy-based subtype irrespective of their semantic role: animate Rs are marked identically to animate Ps (DOM is always attested in languages of this type). Inanimate Rs, in turn, are obliques, and they are marked differently from Ps (both animate and inanimate). Two different manifestations of the animacybased subtype are illustrated in (4) and (5):

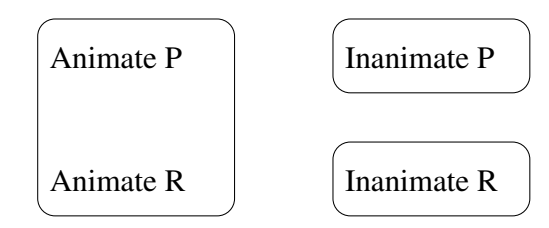

Figure 1. Schematic representation of the animacy-based subtype of the core vs. oblique type 
(4)

Hup (Nadahup; Brazil and Colombia)

a. tiyi? tìh=tch-án wan no?-oh

man 3SG=Son-OBJ knife give-DECL

'The man gave the knife to his son.'

b. Pameriku Pawponsu-án pij deh-an

Americo Alfonso-OBJ cabari village-OBJ

$d=o$ P-ham-yah- eh...

take-go-order-DECL

'Americo sent Alfonso to cabari village ...' (Patience Epps, personal communication)

Korku (Austroasiatic; Munda)

\author{
a. ra:ja ra:ma-ke sita-ke ji-khe-nec \\ king.NOM Ram-oBJ Sita-OBJ give-PAST-PERS \\ 'The king gave Sita to Ram.' (Nagaraja 1999: 46) \\ b. iñj ini-koro-ken mya kamary-Ten Di-ga:w-en \\ I this-man-OBJ one work-ABL that-village-DAT/LOC \\ kul-khe-nej \\ send-PAST-PERS \\ 'I sent this man on a work to that village.' (Nagaraja 1999: 97)
}

In Hup, both animate and inanimate Rs bear the suffix - an, but they are distinguished on the basis of stress. The suffix is stressed if $\mathrm{R}$ is animate (marked with an accent), but it is unstressed if $\mathrm{R}$ is inanimate. In the case of animate Ps, the suffix is stressed as well, which means that animate Rs are formally treated in the same way as animate Ps. Inanimate Ps are zero-marked, i.e., inanimate Rs are formally treated differently from inanimate Ps. They are not coded as core arguments, but as obliques (although the difference to animate Rs is only phonological). In Korku, animate and inanimate Rs bear morphologically distinct case suffixes. Animate Rs occur in the accusative, whereas the dative/locative marker -en is attached to inanimate Rs. As is characteristic of the animacy-based subtype, only the marking of the animate $\mathrm{R}$ and the animate $\mathrm{P}$ coincides in form, while inanimate Rs and inanimate Ps receive different formal treatment. In both languages, inanimate Ps are zero-marked, since both Hup and Korku exhibit DOM, inanimate Rs are formally obliques.

2.1.2. The covert animacy-marking subtype. The other subtype of the core vs. oblique type is represented by languages in which animate Rs also receive the same coding as $\mathrm{P}$, but in contrast to the animacy-based subtype without being overtly marked for animacy. In other words, the languages of this subtype lack DOM and thus overt animacy marking on objects. Identically to the animacy-based subtype, inanimate Rs surface as obliques in the covert 


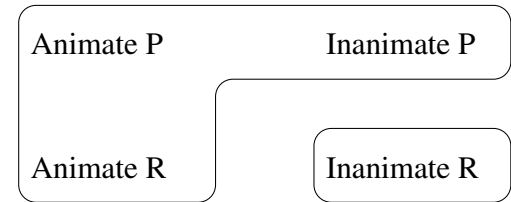

Figure 2. A schematic representation of the covert animacy-marking subtype of the core vs. oblique type

animacy-marking type. The subtype is schematically presented in Figure 2, and two examples are provided in (6) and (7).

(6)

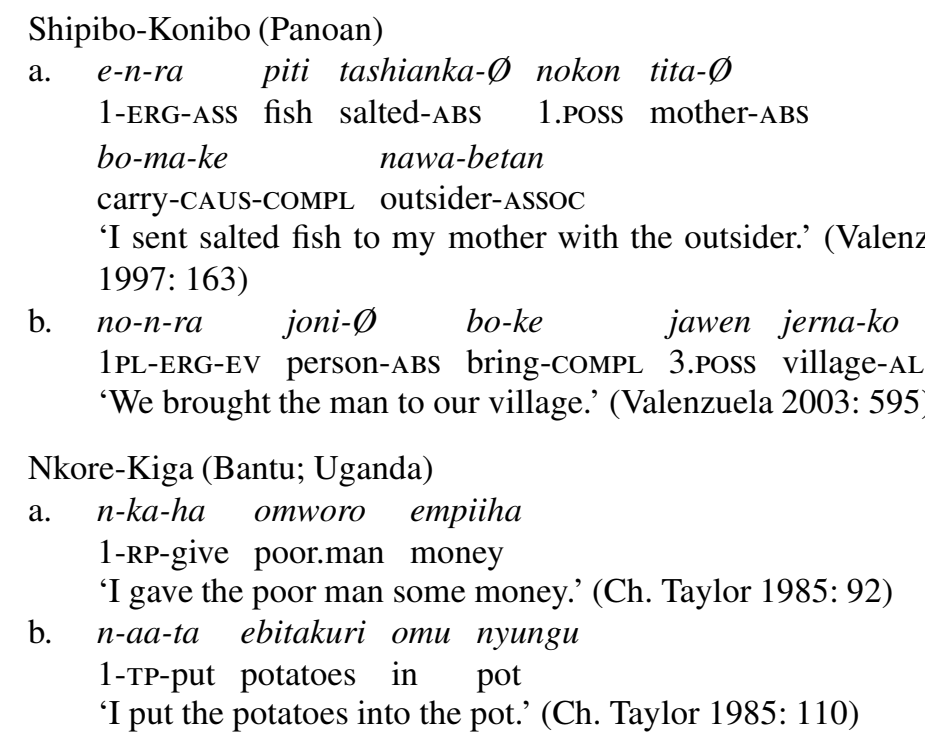

In Shipibo-Konibo, Ps occur in the zero-marked absolutive case regardless of animacy. The absolutive marking extends to animate Rs as well, as shown in (6a). In contrast, inanimate Rs bear overt allative case, as in (6b). Inanimate Rs are thus morphologically obliques. The object marking follows the same principle in Nkore-Kiga, with the difference that this language has no morphological (case) marking on core arguments. Identically to T (and P), animate Rs are zero-marked, i.e., not preceded by a preposition. Inanimate Rs are marked with the preposition omu, as illustrated in (7b), which makes inanimate Rs obliques and renders their marking different from all other objects. ShipiboKonibo and Nkore-Kiga differ from Hup and Korku basically only in that they do not overtly mark their objects for animacy. Only the marking of Rs is sensitive to animacy in the covert animacy-marking type. 
In (6) and (7), animate Rs mandatorily receive the same formal treatment as Ts and Ps. In other languages a similar variation is optional. In these languages, animate Rs may be coded as Ps (whose marking is not sensitive to animacy), but they may also surface as obliques. An example is provided by English, where dative shift applies to animate Rs (as in the professor sent the student a book), but generally not to inanimate Rs (*the professor sent Leipzig a book). Two further examples of similar languages are given in (8) and (9):

$$
\text { Fongbe (Gbe; Benin) }
$$

a. kòkú só àsón ó ná Àsíbá

Koku take crab DEF give Asiba

'Koku gave the crab to Asiba.' (Lefebvre \& Brousseau 2002: 446)

b. kذ̀ku só àkwé ná kùtónû

Koku take money give Cotonou

'Koku gave money to Cotonou [a place name].' (Lefebvre \& Brousseau 2002: 449)

c. kòkú ná Àsíbá àsón

Koku give Asiba crab

'Koku gave Asiba crab.' (Lefebvre \& Brousseau 2002: 445)

d. *kذ̀ku ná kùtónû àkwé

Koku give Cotonou money

'Koku gave Cotonou money.' (Lefebvre \& Brousseau 2002: 448)

(9) Korean (Altaic; Korean)
a. kica-ka enehakca-eykey chayk-ul ponay-ss-ta journalist-NOM linguist-to book-ACC send-PAST-IND 'The journalist sent a/the book to the linguist.'
b. kica-ka wellingten-ulo chayk-ul ponay-ss-ta journalist-NOM Wellington-to book-ACC send-PAST-IND 'The journalist sent a/the book to Wellington.'
c. kica-ka enehakca-lul chayk-ul ponay-ss-ta journalist-NOM linguist-ACC book-ACC send-PAST-IND 'The journalist sent a/the book to the linguist.'
d. *kica-ka wellingten-ul chayk-ul ponay-ss-ta journalist-NOM Wellington-ACC book-ACC send-PAST-IND 'The journalist sent a/the book to Wellington.' (Jae Jung Song, personal communication)

In Fongbe, serial verb constructions may accommodate both animate and inanimate Rs, as shown in $(8 \mathrm{a}, \mathrm{b})$. Animacy-determined formal differences in $\mathrm{R}$ coding arise only if we take dative shift into account: animate Rs may be promoted to $\mathrm{P}$ status via dative shift, while dative shift is not applicable to inanimate Rs (see Lefebvre \& Brousseau 2002: 448). There are no further formal 


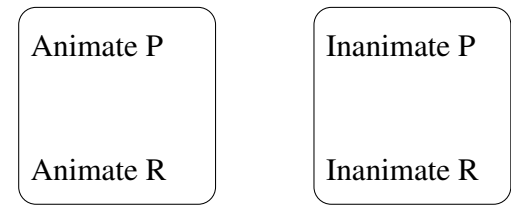

Figure 3. Schematic illustration of Extended Differential Object Marking

differences in R encoding in Fongbe. In Korean, the coding of Rs is invariably conditioned by animacy. The differences are manifested in two ways. First, the form of the oblique case-affixes varies; -eykey marks animate Rs, while -ulo is employed for inanimate Rs. Second, dative shift distinguishes formally between animate and inanimate Rs; only animate Rs allow dative shift, as shown in (9c). Dative shift is not applicable to inanimate Rs, which has the consequence that only animate Rs may receive the formal treatment of Ps in Korean.

\subsection{Extended Differential Object Marking}

The second major type of DRM is represented by languages in which the marking of objects as a whole is conditioned by animacy; animate Rs are marked identically to animate Ps, while inanimate Rs are marked in the same way as inanimate Ps. Animate objects are thus marked in a more elaborate way than inanimate objects regardless of the role they bear, and we may say that DOM has been extended to Rs in this language type, whence the label EDOM. ${ }^{3}$ In contrast to languages of the core vs. oblique type, inanimate Rs cannot be regarded as obliques in EDOM, since they receive the same formal treatment as inanimate Ps and thus qualify as core arguments. A schematic illustration of this type is given in Figure 3.

EDOM in its purest form is illustrated in (10) from Retuarã (only the marking of objects is relevant to the typology proposed here):

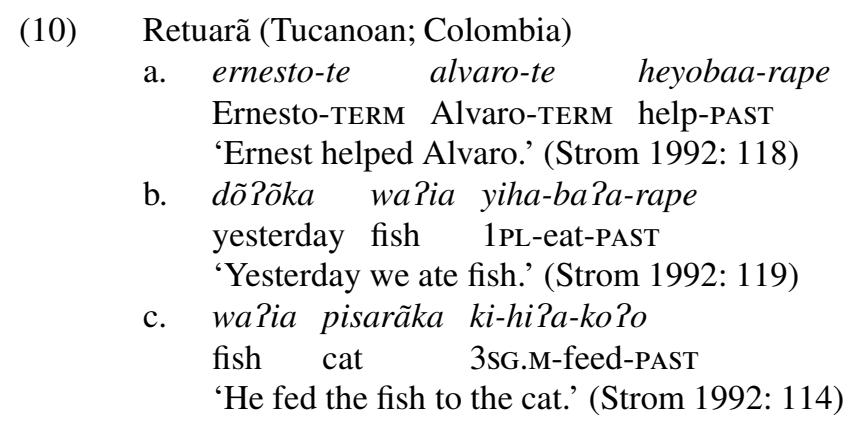

3. The direction of grammaticalization may be reverse, but this is not relevant here. 
d. ko-re ki-re yi-bea-yu

3SG.F-TERM 3SG.M-TERM 1SG-ShOW-PRES

'I show her to him (*I show him to her).' (Strom 1992: 114)

e. anita-re ba?arika îhi-ko?o betania-re

Anita-TERM food give-PAST Bethanie-TERM

'Anita gave the food to Bethanie.' (Strom 1992: 114)

In Retuarã, all arguments referring to human participants take the TERM suffix -tel-re (allomorphs of the same morpheme), while the suffix is not attached to non-human arguments. As a result, all human objects (including P, T, and R) are marked with the suffix, while non-human arguments are unmarked. As for $\mathrm{R}$ coding the variation is then between overtly (human) and zero (non-human) marked Rs.

In (10), the marking of objects as a whole can be explained on the basis of animacy (humanness) alone. Somewhat less thorough/more restricted manifestations of EDOM are attested, e.g., in Nepali and Gujarati:

(11) Nepali (Indo-Iranian; East-Central Indic)

a. sikchak-le eutaa kiitaab maanche-lai pathaa-yo teacher-ERG one book man-DAT send-PAST 'The teacher sent a book to the man.'

b. sikchak-le eutaa kiitaab maisore patha-yo teacher-ERG one book Mysore send-PAST 'The teacher sent the book to Mysore.'

c. maanche-le kiitaab pustakaalaya-ma pathaa-yo man-ERG book library-in send-PAST

'The man sent the book to the library.' (Pawan Choudhary, personal communication)

(12) Gujarati (Indo-Iranian; Central Indic)

a. sikshak-e vidaarthi-ne pustak mokl-y-un

teacher-ERG student-DAT book.N.SG send-PAST.PERF-N.SG

'The teacher sent a/the book to the student.'

b. sikshak-e delhi pustak mokl-y-un

teacher-ERG Delhi book.N.SG send-PAST.PERF-N.SG

'The teacher sent a/the book to Delhi.'

c. sikshak-e pustakalaya-ne pustak mokl-y-un

teacher-ERG library-DAT book.N.SG send-PAST.PERF-N.SG

'The teacher sent a/the book to the library.' (Babu Suthar, personal communication)

Both Nepali and Gujarati display a rather canonical DOM; animate Ps bear dative marking, while inanimate Ps are zero-marked (Pawan Choudhary and Babu Suthar, personal communication; see also Mistry 1997: 426 for Gujarati). 
In addition, DOM is partially retained for Rs too, as the examples above show. In both Nepali and Gujarati, animate Rs bear the same case affix as animate Ps. However, the coding of inanimate Rs distinguishes Nepali and Gujarati from Retuarã. The marking of inanimate Rs is formally split in both Nepali and Gujarati, but in different ways. The two languages give place names zero marking in the $\mathrm{R}$ function. This creates the impression that the principle of EDOM would be at work here as well. However, zero marking is confined to place names, while other inanimate Rs are overtly marked, as shown in (10c) and (11c). In Nepali, other inanimate Rs are morphologically oblique, as they take the locative affix -ma. In Gujarati, the dative affix marking animate objects in general is also used for coding inanimate Rs (other than place names). This means that the animacy requirement, which determines the form of Ps, is relaxed for Rs in Gujarati. The dative marker -ne is thus not a genuine animate object marker in Gujarati.

\subsection{The oblique type}

The last type to be discussed here is represented by languages in which $\mathrm{R}$ coding is sensitive to animacy, but in which Rs never receive the same formal treatment as Ps. This type is accordingly labelled the oblique type, because Rs are always obliques. The type is less relevant to the discussion in the following section, but it is necessary to consider it for completing the proposed formal typology. The type is schematically presented in Figure 4, and two examples are given in (13) and (14).
Finnish (Uralic; Finno-Ugric)
a. lähetti lähett-i
lähettime-n lähettäjä-lle messenger.NOM send-3SG.PAST transmitter-ACC sender-ALL 'A/the messenger sent a transmitter to the sender.'
b. lähetti lähett- $i$ lähettime-n lähetystö-ön messenger.NOM send-3sG.PAST transmitter-ACC embassy-ILL 'A/the messenger sent a transmitter to the embassy.'

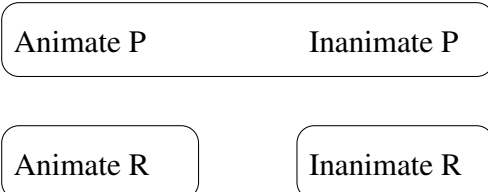

Figure 4. A schematic representation of the oblique type 
Balinese (Western Malayo-Polynesian; Sundic)

a. guru-ne nto ngirim buku sig/*ke anak-e nto teacher-DEF that AV.send book to person-DEF that 'The teacher sent a book to the person.'

b. guru-ne nto ngirim buku ke/*sig Indonesia teacher-DEF that AV.send book to Indonesia 'The teacher sent a book to Indonesia.' (I Wayan Arka, personal communication)

Rs are never coded as Ps in Finnish or in Balinese. In Finnish, P occurs in the accusative, while $\mathrm{R}$ bears either allative (animate) or illative (inanimate) marking (for a more detailed discussion of object marking in Finnish see Huumo 2005). The morphological marking of $\mathrm{R}$ thus varies according to animacy, but it never coincides with the marking of $\mathrm{P}$. In Balinese, the form of the preposition used for $\mathrm{R}$ coding distinguishes between animate and inanimate Rs. The prepositions sig and ke are in complementary distribution; sig marks animate Rs, while ke is employed with inanimate Rs.

\section{The rationale for DRM}

\subsection{Preliminaries}

DRM is an instance of Differential Object Marking if the notion is understood in a broad sense comprising all objects irrespective of their semantic role. In what follows, the applicability of functions typically associated with DOM to DRM will be tested. The explanations discussed independently below overlap to some extent, but they are treated separately for making a more detailed examination possible. The following discussion only concerns languages with some form of DRM. There are numerous languages whose $\mathrm{R}$ marking follows different principles, and which the discussion below does not apply to. Animacy here is regarded as the most important difference between animate and inanimate Rs. It does interact closely with other features (such as affectedness), but these features usually follow from animacy.

\subsection{The marking of prominent, subject-like objects 4}

The marking of prominent objects is often viewed as one of the functions of DOM: overt object coding occurs only if the object approximates the subject in animacy and definiteness (see, e.g., Aissen 2003: 436: "the higher in prominence a direct object is, the more likely it is to be overtly case-marked"). The marking of prominent direct objects also has the function of marking the role of

4. In this section, I will mostly use the labels A and P instead of "subject" and "object", the terms subject and object are used in cases where the reference cited has used these terms. 
object, because animate subjects do not receive the same formal treatment (see Aissen 2003: 437). If subject and object are both formally unmarked, the animate/definite argument is the subject, while the less animate/definite argument is understood as the object.

Animate Rs can also be seen as prominent objects if we associate prominence with animacy (and in some cases definiteness, as in Hindi, where also definite direct objects can bear accusative/dative coding; Bertil Tikkanen, personal communication), which is common practice in most studies dealing with DOM. Consequently, we may claim that the high prominence associated with animate Rs contributes to their formal encoding. However, in contrast to Ps, the marking of prominence seems to lack any obvious function in the case of DRM. The marking of prominence is also associated with role-marking in DOM, because only prominent Ps (and never As) receive overt animacy-based marking. The marking also has the function of distinguishing between prominent and less prominent Ps, because only prominent Ps receive overt accusative (or dative) marking. Neither of these functions seems to capture the nature of DRM very well. Similarly to As, animate Rs are inherently highly prominent arguments due to animacy. The overt non-zero marking of animate Rs lacks the function of distinguishing between more and less prominent animate Rs. If DRM was somehow associated with prominence, we should find variation in the coding of animate Rs as well, but this does not seem to be the case.

\subsection{The (un)markedness of animate goals ${ }^{5}$}

For the markedness analysis to hold for DRM we should be able to show that the more elaborate marking of animate Rs follows primarily from their marked nature. However, in clauses with an animate and an inanimate object, such as 'the teacher sent the student a book', the object with an animate referent usually refers to the goal or the recipient (see also Sedlak 1975: 125 and Blansitt 1988: 175). Animate entities are therefore canonical, unmarked recipients of such transfer events as 'give' or 'buy'. This follows because these events involve reception. Reception usually involves a conscious act by the recipient (accepting the transfer), which renders animate entities typical bearers of the role. Consequently, we cannot explain DRM by markedness. If anything, DRM seems to highlight the UNMARKEDNESS of animate Rs. This hypothesis is also supported by actual linguistic data. In the animacy-based core vs. oblique type and EDOM, overt marking of Rs is confined to animate, i.e., unmarked recipients. The function is thus best regarded as the opposite of that in canonical DOM. Moreover, the oblique treatment of inanimate Rs can be taken to

5. In this section, the labels "goal" and "recipient" are used if it is necessary to distinguish between the roles borne by Rs or if the reference is to the underlying semantic role, not its formal manifestation. 
highlight their marked nature, since inanimate Rs refer to less than canonical recipients, which are unable to complete a transfer event.

The differences in the markedness status of objects in DOM and DRM become understandable if we regard the P/R marker as a marker of animacy instead of markedness. Animacy is an expected (though not entailed) feature of recipients, while inanimate entities are usually patients/themes in events (mainly due to lack of intentionality). On this analysis, animate Rs are (almost) always overtly marked precisely because they are animate, while the marking occurs less frequently with Ps precisely because they are typically inanimate. This is especially evident for the animacy-based core vs. oblique type and EDOM, which use the same element for marking animate Ps and animate Rs. A similar case is attested also in Awa Pit, in which one and the same affix - $t a$ marks both animate Ps and Rs, but in contrast to Retuarã the affix never attaches to animate Ts (see Curnow 1997: 72). On the other hand, this explanation is not very helpful for languages like Shipibo-Konibo, where animacy is not overtly marked.

\subsection{Disambiguation of clauses: Support for the discriminatory view?}

The more elaborate linguistic coding of ontologically marked arguments is intimately related to disambiguation. For example, DOM highlights the markedness of $\mathrm{P}$ and thus distinguishes it from A (only animate Ps may be overtly marked). It is unsurprising that disambiguation is frequently viewed as one of the primary functions of DOM (see, e.g., Foley 1999: 119). There are many languages in which overt argument marking appears only in potentially ambiguous cases (see, e.g., Kittilä 2005). These cases provide us with the best pieces of evidence for the discriminatory view of argument marking according to which arguments are primarily (but not exclusively) marked for keeping arguments (such as A and P) apart.

Based on the close relation of markedness and disambiguation, on the one hand, and the irrelevance of markedness for DRM, on the other, we can predict that disambiguation does not make a major contribution to DRM. This is also what we find. DRM rather yields (formal) ambiguity instead of resolving it, especially in the animacy-based core/oblique type and EDOM. DRM produces constructions with two identically marked objects in the case of clauses denoting such events as 'the father showed the baby to his son' or 'the linguist sent a book to Leipzig'. Identical marking occurs when distinct marking would be necessary for disambiguation. This makes any contribution of disambiguation to DRM rather insignificant. Further evidence for the irrelevance of disambiguation to explaining DRM is provided by languages in which both animate Ps and animate Rs may occur in the accusative, but in which only one of the objects may bear accusative marking at a time. If both $\mathrm{T}$ and $\mathrm{R}$ have an animate 
referent, it is usually the $\mathrm{R}$ that surfaces as an oblique (see Kittilä 2006), i.e., overt animacy marking of $\mathrm{R}$ is dropped when it would be needed for disambiguation (this explanation is not applicable to languages in which inanimate Rs are marked as obliques). It is also important to note that overt marking of animate Rs only highlights contextually retrievable information in clauses denoting canonical transfer events with an animate goal and an inanimate theme. The roles of the objects are usually recoverable from animacy, which renders their overt coding redundant.

We may, however, also claim that the primary function of DRM is to distinguish between two animate arguments, namely A and animate R (see also Foley 1999: 119), not between two objects. This could be claimed to be the conditioning factor of DRM in the core vs. oblique-type and EDOM. If an animate $\mathrm{R}$ is coded as $\mathrm{P}$, we may say that this occurs for the purpose of distinguishing between A and R, very much in the same way as DOM distinguishes between $\mathrm{A}$ and P. In both cases, the marked animate object needs to be distinguished from an animate A. This function is rather evident in languages such as Awa Pit, where an accusative affix marks both animate Ps and animate Rs, but in which the marker cannot attach to $\mathrm{T}$ regardless of its animacy (see Curnow 1997: 72-74). Only one animate argument is marked overtly to avoid confusion. To summarize, we may conclude that disambiguation possibly makes a minor contribution to DRM, but the phenomenon as a whole is not satisfactorily explained by disambiguation. There are cases in which there is potential ambiguity resulting from the equal animacy of the two objects, but in which DRM fails to resolve this ambiguity.

\subsection{The marking of affectedness}

3.5.1. Preliminaries. Affectedness can be defined as the degree at which an action is targeted at the patient (target can be understood as the participant whose state the agent primarily wishes to modify). The degree is higher and the energy flow more forceful in 'the teacher broke the cup' than in 'the teacher touched the cup' (see, e.g., Hopper \& Thompson 1980: 252-253). This renders the patient of the first event more affected. These differences are formally relevant, and in many languages only patients that are directly affected by events are overtly coded as Ps, while less affected patients surface as obliques. Moreover, not only the forcefulness of the energy flow is important, but animate (especially human) and inanimate entities differ from each other in how they register the effects of events. Inanimate entities register the effects of events without any further consequences. On the other hand, animate entities are also capable of experiencing physical pain and feelings. This means that the same event may affect an animate patient in more ways than it affects an inanimate patient, which makes the degree of overall affectedness higher for animate pa- 
tients (cf. also Naess 2004: 1202). Affectedness thus makes a contribution to DOM, even though it is usually neglected in studies of DOM. An exception to this is represented by Naess (2004), who proposes that it is the high degree of affectedness associated with animate and definite Ps, not mere animacy or definiteness that primarily conditions DOM. This means that animate and highly definite Ps are marked, because they are perceived as more affected, not only because they are animate. This is, however, not to say that animate patients are always more affected than inanimate patients. For example, inanimate patients of 'break' are more affected than animate targets of 'watch' or 'hear'.

It is easy to find examples of cases where affectedness unarguably conditions the marking of Rs as well. Examples include languages like Dutch (Janssen 1998: 281), Sochiapan Chinantec (Foris 1998: 213), and Zulu (J. Taylor 1998: 75-76), where double object frames (e.g., 'the linguist sent the agronomist a flower') indicate a higher degree of affectedness of the goal than transitive frames with an oblique (e.g., 'the linguist sent a flower to the agronomist', see Kittilä 2007 for more examples). In such languages, Rs referring to affected participants coincide in form with $\mathrm{P}$, while less affected Rs are rather obliques (this is especially evident in the core vs. oblique type). It is also important to note here that (as was shown in Section 2) animate Rs are usually coded as Ps in languages displaying the core vs. oblique type or EDOM. This close relation of animacy and affectedness and the applicability of affectedness to explaining DRM will be examined below.

3.5.2. Co-variation of animacy/definiteness and affectedness. As was noted above, recipients of 'give' or 'buy' are usually animate. There are even languages which disallow inanimate recipients (see also Blansitt 1973: 7). As with animate Ps, all animate Rs receive the same formal treatment, because the marking is operationalized in terms of a more salient feature, namely animacy (cf. Naess 2004: 1203 for Ps). In other words, in languages with DRM all animate Rs receive the same formal marking irrespective of other features of transitivity, only animacy and the high degree of affectedness following from that are relevant to the coding of Rs.

The brief discussion above may lead us to believe that the co-variation of animacy and affectedness indeed primarily conditions DRM. However, an analysis based on the assumption that animate goals are inherently more affected than inanimate goals, only because of animacy, leaves too many questions unanswered. The most important of these is what exactly renders animate goals more affected than inanimate goals. An explanation based on the forcefulness of the energy flow is not very helpful, because the energy flow is the same in 'the teacher sent the book to the student' or 'the teacher sent the book to the school'. On the other hand, the fact that events usually affect animate participants also in other ways in addition to the mere effects of the energy flow seems 
more useful here. The transfer may continue to affect an animate goal after the transfer itself has been completed, animate goals, for example, may use the transferred entity for their purposes (in a similar vein, animate patients may experience pain or feeling after the event itself has been completed). Let us say receiving an amount of money has no directly observable effect on an animate goal per se. The effects become salient only if the recipient uses the transferred money for a specific purpose such as buying a house. With inanimate entities the affectedness does not extend beyond the completing of the transfer (see below for elaboration). The nature of affectedness of recipients is very different from the affectedness of patients, but what is important here is the intimate relation of affectedness and animacy. Because only animate entities are capable of using a transferred entity for these kinds of purposes, animate goals are affected by transfer events in a more salient way.

3.5.3. Animate goals as the most affected participants of transfer events. Patients are unarguably the most directly and dramatically affected participants of canonical transitive events, because they are the only saliently affected participants present. On the other hand, events of transfer involve two affected participants, theme and goal, both of which can in principle be regarded as the most affected participant of this event type. There are, however, valid reasons for regarding animate goals as the primarily affected participants of transfer events. First, due to the usually higher degrees of affectedness associated with animate entities, animate goals qualify as the primarily affected participants of transfer events (see above). Second, we may also say that transfer only has a minor effect on the theme in that only their location changes. The effects are at any rate less dramatic than those resulting from highly transitive events such as 'kill' or 'break'. Also in this regard, animate goals constitute the most affected participants of transfer events, even though the affectedness is less direct than in the case of canonical patients (see Section 3.5.2).

However, things change if both the theme and the recipient are animate. Mere animacy does not make it possible to decide which of the two non-agent participants is affected by the event in a more thorough fashion. An event of transfer may have other kinds of more dramatic effects (apart from the mere change of location) on an animate theme in cases such as 'the father gave his daughter to the man (in marriage)' or 'the farmer sold his cows to the butcher'. The degree of (mental) affectedness associated with the animate theme may be higher than the affectedness of the goal, which is formally manifest in languages such as Lango and Sahaptin, as shown in (15) and (16) (see further Kittilä 2006): 
(15)

Lango (Nilotic)

a. lócə òmİyá búk

man 3sG.give.PERF.1sG book

'The man gave me the book.' (Noonan 1992: 121)

b. lócə òmìy bòts

man 3sG.give.PERF.3SG to.1sG

'The man gave him (e.g., a slave) to me.' (Noonan 1992: 121)

(16) Sahaptin (Penutian)

a. pa-ní-ya k'úsi miyúux-na

3PL.NOM-give-PAST horse chief-OBJ

'They gave the horse to the chief.' (Rude 1997: 334)

b. pa-ní-ya tílaaki miyúux-na

3PL.NOM-give-PAST woman chief-OBJ

'They gave the woman to the chief.' (Rude 1997: 334)

c. pa-ní-ya tílaaki-na miyuux-mí-yaw

3PL.NOM-give-PAST woman-OBJ chief-GEN-ALL

'They gave the woman to the chief.' (Rude 1997: 334)

Examples (15a) and (16a) describe canonical transfer events with an animate goal and an inanimate (or non-human) theme. In Lango, $\mathrm{R}$ is treated the same as $P$ in this case, which means that $R$ is cross-referenced in the verb, while $\mathrm{T}$ is not. In Sahaptin, animate $\mathrm{R}$ bears overt marking (the same marker optionally marks animate/definite Ps, see Rude 1997: 327), while inanimate T is morphologically zero-marked. In this regard, Lango and Sahaptin are very typical primary/secondary object-languages in the spirit of Dryer 1986. What makes (15) and (16) interesting is the coding of the events in (15b) and (16b, c). These clauses denote transfer events with an animate theme and an animate goal. In Lango, $\mathrm{T}$ receives the same formal treatment as $\mathrm{P}$ in this case, which means that it is cross-referenced in the verb. In Sahaptin, either T or R (but not both) can be coded as P. This kind of coding is not possible for inanimate Ts. In both Lango and Sahaptin, $\mathrm{R}$ is as an oblique if $\mathrm{T}$ is animate (in Sahaptin, this is optional).

3.5.4. Animate goals (recipients) and patients as the primary targets of events. Because patients are the only (directly) affected participants of monotransitive events, it is only natural that they are also considered their primary targets (understood as the participant whose state the agent primarily wishes to modify). The agent of typical transitive events such as 'the teacher painted the house' thus intends to modify the state of the patient. On the other hand, transfer events have two potential primary targets, since they involve two non-agent participants. 
In light of the definition above, animate goals are better candidates for primary targets than inanimate themes. It is more probable that the agent of an event such as 'the father sent the money to his child' intends to cause a change in the animate goal's state rather than in the state of the inanimate theme. After the transfer has been successfully completed, the animate goal (recipient) may use the transferred entity for his/her purposes. The transferred entity (money) is only a means of achieving a change in the animate goal's state. This also means that the affectedness of the theme follows from the need to affect the state of the animate goal. It is, of course, true that the agent needs to direct the energy flow at the theme first in an event such as 'send' before any effect on the animate goal may follow. However, if we define the primary target of an event as the participant whose state the agent primarily wishes to modify, it is clear that the animate goal is the primary target of this event. In a similar vein, it is more natural to say that 'the window' is the primary target of an event such as 'the criminal broke the window with a rock', even though the instrument needs to be manipulated before there is any effect on the patient. The instrument is only a means of modifying the state of the patient.

\subsection{Theoretical implications}

DRM and the discussion above have consequences for our understanding of object marking as a uniform phenomenon. First, even though Ps and Rs have usually been kept apart in studies of the motivation of object marking, the discussion above has shown that a more holistic approach to object marking is also possible. This article lends support to the view that affectedness is the key feature in explaining the special formal treatment of animate objects (see Naess 2004). This is even more straightforward for DRM than for DOM in that the other explanations fail to account for DRM, while they are to varying degrees relevant to DOM. We may therefore conclude that affectedness provides us with a better starting point than animacy, markedness, or disambiguation if we aim at a uniform explanation for Differential Marking of Objects. Moreover, inanimate goals and inanimate patients along with other less than fully affected non-agent participants receive a formal treatment different from that given to animate goals/transitive patients, and they are usually coded as obliques. This underlines the importance of animate and affected objects.

As regards the two views of argument marking, namely the discriminatory view (see, e.g., Comrie 1978: 379 and Dixon 1979: 69) and the indexing view (see, e.g., Hopper \& Thompson 1980), DRM clearly supports the indexing view. According to the discriminatory view, the primary function of argument marking is to distinguish between arguments of clauses. The indexing view, in turn, states that only arguments that approximate a semantically defined prototype can receive a certain kind of formal treatment (e.g., as an A or as 
a P, see Hopper \& Thompson 1980). DRM has no important discriminatory functions (see Section 3.5.3), which makes the discriminatory view inapplicable to explaining DRM and consequently the marking of objects as a uniform phenomenon. We may also add that the discriminatory view fails to account for DOM in absolutive-ergative languages, because the ergative marking of A suffices for discrimination, and accusative marking of $\mathrm{P}$ is thus redundant. In DRM (core vs. oblique type and EDOM), only animate Rs may receive the formal treatment of P, i.e., only specific kinds of arguments may be coded this way, which is in accordance with the indexing view. Consequently, animacy can rather be regarded as a prototypical feature of objects due to its intimate relation with affectedness (affected objects are seen as prototypical, see Hopper \& Thompson 1980: 252 and Naess 2004). Only affected objects are coded as core arguments, and moreover, both DOM and DRM manifest the principle that the most affected participant of an event is coded as P (see Dixon 1994: 8). We may thus speak of the Differential Marking of Objects as a uniform phenomenon conditioned primarily by affectedness. This is not to abandon the discriminatory view altogether, since it clearly makes a contribution to the argument marking in a number of languages (see Kittilä 2005).

\section{Conclusions}

This article has investigated the effects of animacy on the encoding of R from a crosslinguistic perspective. Based on how animacy affects $\mathrm{R}$ encoding, languages were divided into three types labelled as the core vs. oblique type, Extended Differential Object Marking, and the oblique type. These differences were largely based on whether the language in question displays DOM or not or whether a given language may treat Rs the same as Ps. As regards the underlying motivation of DRM, the discussion in the article supports Åshild Naess' claims that it is rather affectedness than markedness or disambiguation that conditions DRM (and Differential Marking of Objects in general).

The examination of DRM also has consequences for our understanding of object marking and argument marking in more general terms. Because the typical functions of DOM fail to account for DRM, Differential Marking of Objects (comprising both direct and indirect objects) is better explained by affectedness. Moreover, this makes the indexing view of argument marking more applicable to explaining argument marking in more general terms. In both DOM and DRM, only affected objects are marked, which is compatible with the indexing view. This is not to deny the relevance of the discriminatory view altogether, but in general the indexing view seems to explain argument marking better.

The present study is (to the best of my knowledge) the first thorough crosslinguistic analysis of DRM, raising many issues that deserve to be investigated 
in more detail. Perhaps the most interesting of these is the crosslinguistic distribution of the three types. It is not possible to make any generalizations about the distribution of the types in light of the data presented here, but a larger sample of languages is needed for this. It should also be noted that the present article has illustrated the three types of DRM as rather consistent marking strategies. It is, however, possible (and even probable) that the overall picture of DRM is not so uniform. Examples of this were given in (11) and (12), in which EDOM is confined to animate Rs and place names. Consequently, detailed studies of DRM in individual languages are needed. For example, the exact semantic role (recipient vs. goal) borne by Rs is potentially relevant in this regard. Instances of this are found also in English where the encoding of inanimate Rs is partly split. Dative shift is utterly ungrammatical in case R clearly bears the role of a goal, as in the professor sent a student to the field/*the professor sent the field a student. On the other hand, dative shift becomes more felicitous if an inanimate goal can be regarded as some kind of recipient, as in the professor sent a book to the library/the professor sent the library a book. Similar variation may very well be attested in other languages, too.

Received: 28 November 2005

Helsingin yliopisto

Revised: 5 November 2007

Correspondence address: Yleisen kielitieteen laitos, PL 9, 00014 Helsingin yliopisto, Finland; e-mail: kittila@mappi.helsinki.fi

Acknowledgements: The Academy of Finland (Grant No. 105771) has provided financial support for this study. I would like to express my gratitude to the following people for providing me with data from languages of their expertise (names in alphabetical order): Mengistu Amberber, Azeb Amha, Nino Amiridze, I Wayan Arka, Rolando Felix Armendariz, Jóhanna Barđdal, Pawan Choudhary, Agurtzane Elordui, Pattie Epps, Stefan Georg, Lotta Harjula, Omkar N. Koul, Amina Mettouchi, Steve Nicolle, Sylvester Osu, Diego Quesada, Stephane Robert, Jae Jung Song, Babu Suthar, Saliem Leghese Tesfazghi, Bertil Tikkanen, and Kashi Wali. I would also like to thank Daniela Frerick, Tuomas Huumo, and the referees of this article for their invaluable feedback on an earlier version. I would also like to thank Jack Rueter for improving my English. All the remaining flaws are naturally my own responsibility.

Abbreviations: $2 / 3$ 2nd/3rd person; ABL ablative; ABS absolutive case; ACC accusative case; ALL allative case; ASs assertative; ASSOC associative case; AV agentive voice; CAUS causative; COMPL completive; DAT dative case; DECL declarative; DEF definite; ERG ergative case; EV evidential; F feminine; GEN genitive; ILL illative case; IND indicative; INSTR instrumental case; LOC locative case; M masculine; N neuter; NOM nominative case; OBJ object; PAST past tense; PERF perfective; PERS person marker; PL plural; POSS possession; PRES present tense; RP remote past; SG singular; TERM marker of animate arguments; TP today past.

\section{References}

Aissen, Judith. 2003. Differential object marking: Iconicity vs. economy. Natural Language \& Linguistic Theory 21. 435-483. 
Blake, Barry J. 1994. Case. Cambridge: Cambridge University Press.

Blansitt, Edward L. Jr. 1973. Bitransitive clauses. Working Papers on Language Universals 13. 1-26. Stanford, CA: Stanford University.

Blansitt, Edward L. Jr. 1988. Datives and allatives. In Michael Hammond, Edith Moravcsik \& Jessica Wirth (eds.), Studies in syntactic typology, 173-191. Cambridge: Cambridge University Press.

Bossong, Georg. 1985. Empirische Universalienforschung: Differentielle Objektmarkierung in den neuiranischen Sprachen. Tübingen: Narr.

Comrie, Bernard. 1978. Ergativity. In Winfred P. Lehmann (ed.), Syntactic typology, 329-394. Hassocks, Sussex: Harvester.

Comrie, Bernard. 1989. Language universals and linguistic typology. Chicago: University of Chicago Press.

Curnow, Timothy. 1997. A grammar of Awa Pit (Cuaiquer), an indigenous language of southwestern Colombia. Canberra: Australian National University doctoral dissertation.

Dixon, R. M. W. 1979. Ergativity. Language 55. 59-138.

Dixon, R. M. W. 1994. Ergativity. Cambridge: Cambridge University Press.

Dryer, Matthew. 1986. Primary objects, secondary objects, and antidative. Language 62. 808-845.

Ebert, Karen. 1997. Camling. München: Lincom Europa.

Foley, William A. 1999. Grammatical relations, information structure, and constituency in Watam. Oceanic Linguistics 38. 115-138.

Foris, David. 1998. Sochiapan Chinantec GIVE: A window into clause structure. In Newman (ed.) 1998, 209-248.

Haspelmath, Martin. 2005. Argument marking in ditransitive alignment types. Linguistic Discovery 3(1). 1-21. http://journals.dartmouth.edu/cgi-bin/WebObjects/Journals.woa/2/xmlpage/ $1 /$ article/280

Haspelmath, Martin. 2007. Ditransitive alignment splits and inverse alignment. Functions of Language 14. 79-102.

Hopper, Paul J. \& Sandra A. Thompson. 1980. Transitivity in grammar and discourse. Language 56. 251-299.

Huumo, Tuomas. 2005. How fictive dynamicity motivates aspect marking: The riddle of the Finnish quasi-resultative constructions. Cognitive Linguistics 16. 113-144.

Janssen, Theo A. J. M. 1998. Giving in Dutch: An intra-lexematical and inter-lexematical description. In Newman (ed.) 1998, 267-306.

Kittilä, Seppo. 2005. Optional marking of arguments. Language Sciences 27. 483-514.

Kittilä, Seppo. 2006. The woman showed the baby to her sister: On resolving humanness-driven ambiguity in ditransitives. In Leonid Kulikov, Andrej Malchukov \& Peter de Swart (eds.), Case, valency and transitivity, 291-308. Amsterdam: Benjamins.

Kittilä, Seppo. 2007. On the encoding of transitivity-related features on the indirect object. Functions of Language 14. 149-164.

Lazard, Gilbert. 1998. Actancy. Berlin: Mouton de Gruyter.

Lefebvre, Claire \& Anne-Marie Brousseau. 2002. A grammar of Fongbe. Berlin: Mouton de Gruyter.

Mallinson, Graham \& Barry J. Blake. 1981. Language typology: Cross-linguistic studies in syntax. Amsterdam: North-Holland.

Mistry, P. J. 1997. Objecthood and specificity in Gujarati. In Jane H. Hill, P. J. Mistry \& Lyle Campbell (eds.), The life of language: Papers in linguistics in honor of William Bright, 425442. Berlin: Mouton de Gruyter.

Naess, Åshild. 2004. What markedness marks: The markedness problem with direct objects. Lingua 114. 1186-1212.

Nagaraja, K. S. 1999. Korku language: Grammar, texts, and vocabulary. Tokyo: Institute for the Study of Languages and Cultures of Asia and Africa.

Newman, John (ed.). 1998. The linguistics of giving. Amsterdam: Benjamins. 
Noonan, Michael. 1992. A grammar of Lango. Berlin: Mouton de Gruyter.

Pilot-Raichoor, Christiane. 1991. Le badaga, langue dravidienne: Description et analyse. Paris: Université de Paris III (Sorbonne Nouvelle) doctoral dissertation.

Pilot-Raichoor, Christiane. 1994. L'objet en badaga. Bulletin de la Société de Linguistique de Paris 89(1). 359-397.

Rude, Noel. 1997. Dative shifting and double objects in Sahaptin. In Talmy Givón (ed.), Grammatical relations: A functionalist perspective, 323-349. Amsterdam: Benjamins.

Sedlak, Philip A. S. 1975. Direct/indirect object word order: A cross-linguistic analysis. Working Papers on Language Universals 18. 117-164. Stanford, CA: Stanford University.

Strom, Clay. 1992. Retuarã syntax. Dallas: SIL.

Taylor, Charles. 1985. Nkore-Kiga. London: Croom Helm.

Taylor, John R. 1998. Double object constructions in Zulu. In Newman (ed.) 1998, 67-96.

Valenzuela, Pilar M. 1997. Basic verb types and argument structures in Shipibo-Conibo. Eugene, OR: University of Oregon master's thesis.

Valenzuela, Pilar M. 2003. Transitivity in Shipibo-Konibo grammar. Eugene, OR: University of Oregon doctoral dissertation. 